\title{
Achalasia mimicking lung abscess
}

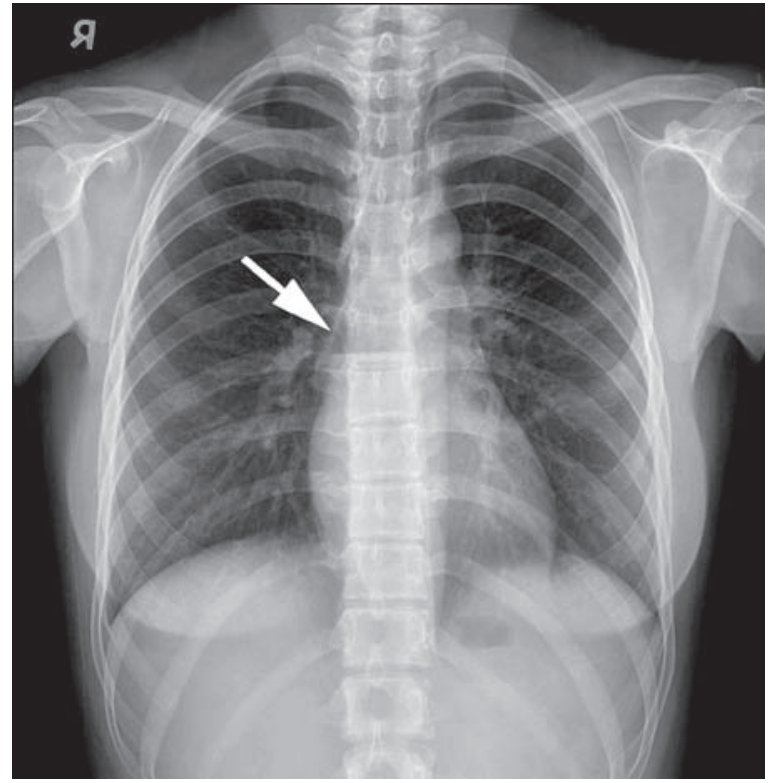

Fig. 1

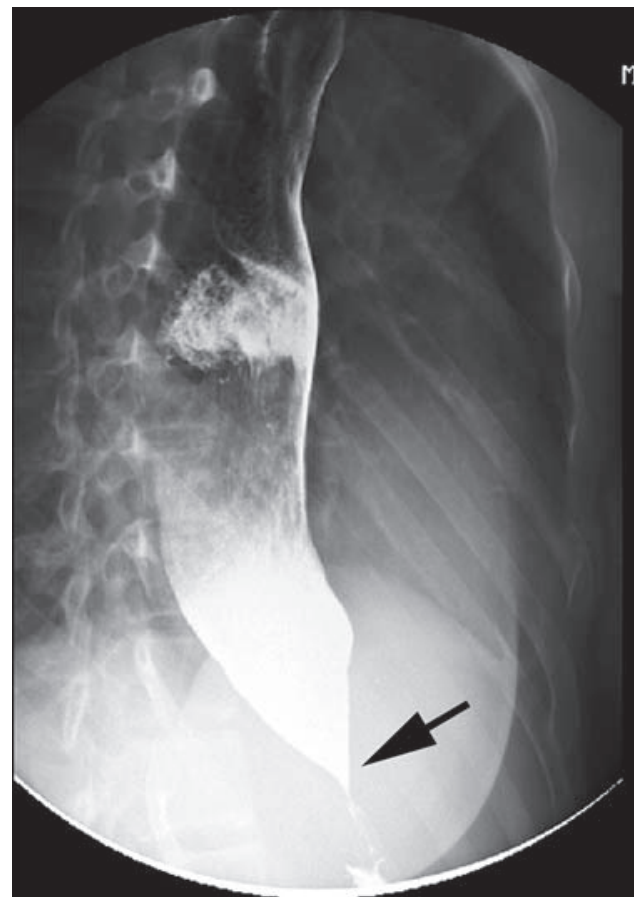

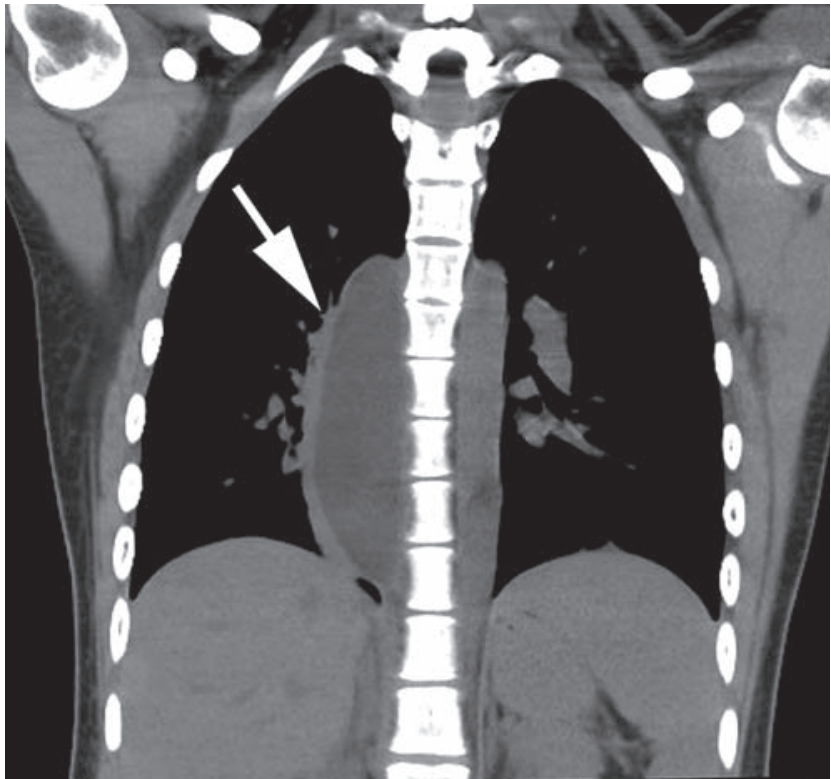

Fig. 2

A 21-year-old woman was hospitalized to our institution on account of fever and chest tightness for a day. Prior to this admission, she was discharged from other hospital 3 weeks ago with a diagnosis of pneumonia. The patient sustained intermittent chest pain after meals that were relieved by vigorous vomiting, along with a weight loss of $5 \mathrm{~kg}$ in the past 6 months. Patient came for medical advice at our chest clinic, where chest radiograph showed a cyst with air-fluid level below the carina (Fig. 1 arrow). After hospitalization, she underwent a chest computerized tomography, in which a dilated esophagus with food retention was detected (Fig. 2 arrow). In addition, a barium swallow study demonstrated characteristics of achalasia, including the bird's beak deformity and a dilated esophagus (Fig. 3). Achalasia was confirmed by an esophageal manometric study.

Hsuan-Wei Chen, Ching Tzao, Chih-Feng Chian

\section{Acknowledgement}

We thank the patient for kindly consenting to publish the photograph.

\section{Conflict of interest}

None declared.

Key words: Lung abscess, achalasia.

Fig. 3

Correspondence: Chih-Feng Chian, M.D., Division of Pulmonary and Critical Care Medicine, Department of Internal Medicine, Tri-Service General Hospital, 325, Sec. 2, Chen-Kung Rd., Neihu District, Taipei City 114, Taiwan, E-mail: sonice3982@yahoo.com.tw 